\title{
Correction to: Psychometric evaluation of the Pinocchio Illusion Questionnaire
}

\author{
John R. Purcell ${ }^{1,2}$ • John Chen ${ }^{1}$ - Alexandra B. Moussa-Tooks ${ }^{1,2}$ - William P. Hetrick ${ }^{1,2,3}$
}

Published online: 15 May 2020

(C) The Psychonomic Society, Inc. 2020

\section{Correction to: Attention, Perception, \& Psychophysics https://doi.org/10.3758/s13414-020-02011-4}

The authors would like to correct the following:

1. The caption for Table 3 states: "Blank spaces indicate less than 0.03 factor loading" when it should indicate "Blank spaces indicate less than 0.30 factor loading."

2. There is an unneeded bracket in the abstract of the paper, the following sentence should have read: "Additionally, decreased reports of PI-specific perceptual aberrations during two elicitations of the PI on the PIQ's open-ended free-response section (percentage of sample endorsement $=5 \%$, [first elicitation]; $8.3 \%$ [second elicitation]) compared with its 11 -item section (endorsement of PI-specific items ranging from $30 \%$ to $53.33 \%$ [first]; $31.67 \%$ to $46.67 \%$ [second]) suggest that these responses may be heavily influenced by demand characteristics rather than accurately capturing PI perception."

Publisher's note Springer Nature remains neutral with regard to jurisdictional claims in published maps and institutional affiliations.

The online version of the original article can be found at https://doi.org/ $10.3758 /$ s13414-020-02011-4

William P. Hetrick

whetrick@indiana.edu

1 Department of Psychological and Brain Sciences, Indiana University, 1101 E. 10th St., Bloomington, IN 47408, USA

2 Program in Neuroscience, Indiana University, Bloomington, IN, USA

3 Department of Psychiatry, Indiana University School of Medicine, Indianapolis, IN, USA 